\title{
Expression of the Epidermal Growth Factor Receptors and Ligands in Paired Samples of Normal Breast Tissue, Primary Breast Carcinomas and Lymph Node Metastases
}

\author{
Anja Brügmann"1,2*, V. Jensen³, J. P. Garne4, E. Nexo², B. S. Sorensen ${ }^{2}$ \\ ${ }^{1}$ Institute of Pathology, Aalborg Hospital, Aalborg, Denmark \\ ${ }^{2}$ Department of Clinical Biochemistry, Aarhus University Hospital, Aarhus, Denmark \\ ${ }^{3}$ Institute of Pathology, Aarhus University Hospital, Aarhus, Denmark \\ ${ }^{4}$ Department of Breast Surgery, Aalborg Hospital, Aalborg, Denmark \\ Email: ${ }^{*}$ ahb@rn.dk
}

Received 6 February 2014; revised 6 March 2014; accepted 13 March 2014

Copyright (C) 2014 by authors and Scientific Research Publishing Inc.

This work is licensed under the Creative Commons Attribution International License (CC BY). http://creativecommons.org/licenses/by/4.0/

(c) (i) Open Access

\section{Abstract}

Purpose: In breast cancer, the EGF receptors host an increasing number of therapeutic targets and the interactive mechanisms of actions of the receptors and their ligands justify investigation of the EGF family as an entity. Experimental design: Paired tissue samples of normal breast tissue and primary breast carcinomas were examined in a prospective study of 163 patients. A third sample was obtained from the paired ipsilateral metastatic lymph node from 58 of these patients. The mRNA expression of four EGF receptors (HER1 - HER4) and 11 activating ligands was quantified with real-time RT-PCR. Results: Expression of HER2, HER3, and HER4 mRNA was upregulated in primary carcinomas compared to normal breast tissue while HER1 was downregulated. The mRNA expression of HER3 and HER4 differed between primary breast carcinomas and lymph node metastases whereas there was no difference in the expression of HER1 and HER2. The combination of low HER3 and low HER4 expression in the primary carcinoma was significantly more frequent in lymph node-negative patients as compared to lymph node positive patients. Distinct correlation patterns of the receptors and their corresponding activating ligands appeared in both normal breast tissue and in carcinomas, notably for the HER3 and HER4 receptors and their 3 specific ligands: HB-EGF, NRG2, and NRG4. Conclusion: HER2, HER3, and HER4 showed increased mRNA expression in carcinomas and were positively correlated to each other and to specific activating ligands. Furthermore, low HER3 and HER4 expression in the carcinomas correlated to the absence of lymph node metastases.

${ }^{*}$ Corresponding author.

How to cite this paper: Brügmann, A., et al. (2014) Expression of the Epidermal Growth Factor Receptors and Ligands in Paired Samples of Normal Breast Tissue, Primary Breast Carcinomas and Lymph Node Metastases. Advances in Breast Cancer Research, 3, 22-37. http://dx.doi.org/10.4236/abcr.2014.32005 


\section{Keywords}

\section{Breast Cancer, Lymph Node Metastases, EGF Receptors, EGF Ligands, RT-PCR}

\section{Introduction}

In breast cancer, the family of epidermal growth factor (EGF) receptors is the target of an increasing number of therapeutic drugs [1] [2]. Traditionally, the biomarkers decisive for targeted treatment are evaluated in the primary breast carcinoma although the target is the metastatic cells and the minimal residual disease. Axillary lymph node metastases are the detectable clinical manifestation of metastatic cells.

The primary route for the metastatic spread of breast carcinoma is via the lymphatic system, and the axillary lymph node status remains the best prognostic factor [3] [4]. Assuming that the lymph node metastases represent a migrated fraction of the primary tumor cells, the metastatic cells would, conceivably, share an identical molecular profile [5]. Recent research has shown that the heterogeneity and clonal diversity seen in breast cancer contradict this notion [6]-[11].

In view of these findings, we analyzed the expression of all the human epidermal growth factor (EGF) receptors and their activating ligands in primary breast carcinoma and correlated it with their expression in the axillary lymph node metastasis and with normal breast tissue.

The EGF family comprises four structurally similar tyrosine kinases known as human epidermal growth factor receptor 1 to 4 (HER1-4). The receptors are abundant in numerous epithelia where their normal cell functions involve proliferation, differentiation, apoptosis, migration, and angiogenesis [1] [12]. In several epithelial cancers, including breast cancer, dysregulation of EGF receptors and their functions promotes carcinogenesis [13]-[15]. EGF receptors are transmembrane glycoproteins with an extracellular ligand-binding domain. The activating ligands are receptor specific [16]. The Epidermal growth factor (EGF), amphiregulin (AMPH), and transforming growth factor- $\alpha$ (TGF- $\alpha$ ) activate HER1. Heparin-binding EGF-like growth factor (HB-EGF), epiregulin (EPR), and betacellulin (BTC) activate both HER1 and HER4. The neuregulins (NRG) activate HER3 and HER4 [17] [18]. HER2 has no activating ligand, but possesses a constitutively active conformation activated upon dimerization. Ligand binding facilitates hetero- or homodimerization between two EGF receptors. This dimerization leads to cross phosphorylation of intracellular tyrosine kinase domains, and docking sites for signaling proteins are created.

Conceptually, the complex and interactive mechanisms of actions of the EGFR family, justifies investigation of all four receptors of the EGF family as an entity [18]-[20] as a supplement to the studies describing the receptors individually. Comparative studies exist on the HER2 expression in the primary tumors, lymph node metastases, and distant metastases [21]-[24]. In these studies semi-quantitative methods were used and the samples collected at different time points during the disease, primarily from distant metastases. Overall HER2 tends to correlate well between primary tumors and metastatic sites but significant variations in discordance rates have been reported (2\% - 27\%) [25]. Cardoso et al. studied the correlation of HER2 in primary breast carcinoma and lymph node metastases in a large archival material $(n=370)$ [11]. In this study the overall percentage of discordant marker status was $2 \%$; however, for the tumors that were lymph-node positive, $15 \%$ were negative in the primary tumor. The HER2 study by Santiago et al. of 52 breast carcinomas and matched axillary metastasis showed an $88.5 \%$ concordance using IHC and 98\% using FISH [26]. They concluded that HER2 status is stable during axillary metastatic progression.

In this study, we made a point in determining correlation using a quantitative method (real-time RT-PCR) at the time of primary surgery. At this point in the time course of the disease, the clinical decisions regarding adjuvant therapies are taken for each individual patient. We correlated the expression of the EGF receptors and their ligands in paired samples of primary breast carcinomas and corresponding lymph node metastases. Furthermore, we investigated whether their expression in the primary carcinomas could predict the metastatic status of the axillary lymph node.

\section{Materials and Methods}

The Regional Ethics Committee Northern Jutland, Denmark, approved this prospective cohort study, and signed informed consent was obtained from each patient (N-20070047). 


\subsection{Patients}

One hundred and seventy-nine women with primary operable breast cancer treated at the Department of Breast Surgery, Aalborg Hospital, participated in the study. Inclusion took place during the prevalent screening phase. Patients with a medical history of cancer and patients treated with neoadjuvant therapy were not included. Patients with multicentric cancers were excluded $(n=12)$. Furthermore, 4 patients were excluded because they had a noninvasive lesion (ductal carcinoma in situ) or the invasive focus was less than $3 \mathrm{~mm}$. Tissue specimens were successfully examined in 163 patients (Figure 1). The clinicopathological characteristics of the cohort are listed in Table 1.

\subsection{Tissue Specimens}

Breast tissue specimens were obtained from primary breast cancer surgical procedures. The samples were prospectively collected from November 2008 to May 2010 from unfixed mastectomy or lumpectomy specimens. All tissue specimens were transported on ice from the operating room to the Institute of Pathology, Aalborg Hospital. The normal breast tissue, tumor specimens, and lymph node samples were all frozen in liquid nitrogen within a mean period of 40 (95\% c.i.: 39 to $42 \mathrm{~min}$, range 20 to 79) minutes after surgical removal. A pilot study performed on samples from 10 patients showed stable mRNA quantities of HER1-4 at 15, 30, and 60 minutes after surgical removal (unpublished data), and similar results have been published by Ohashi et al. [27].

Normal breast tissue was sampled during macroscopic pathoanatomical examination by experienced breast pathologists. The distance between the location for tumor sampling and normal breast tissue sampling was measured in the surgical resections $(n=158)$. The mean distance was $48 \mathrm{~mm}$ (95\% c.i.: 43 to 53 mm, range: 4 to $150 \mathrm{~mm})$.

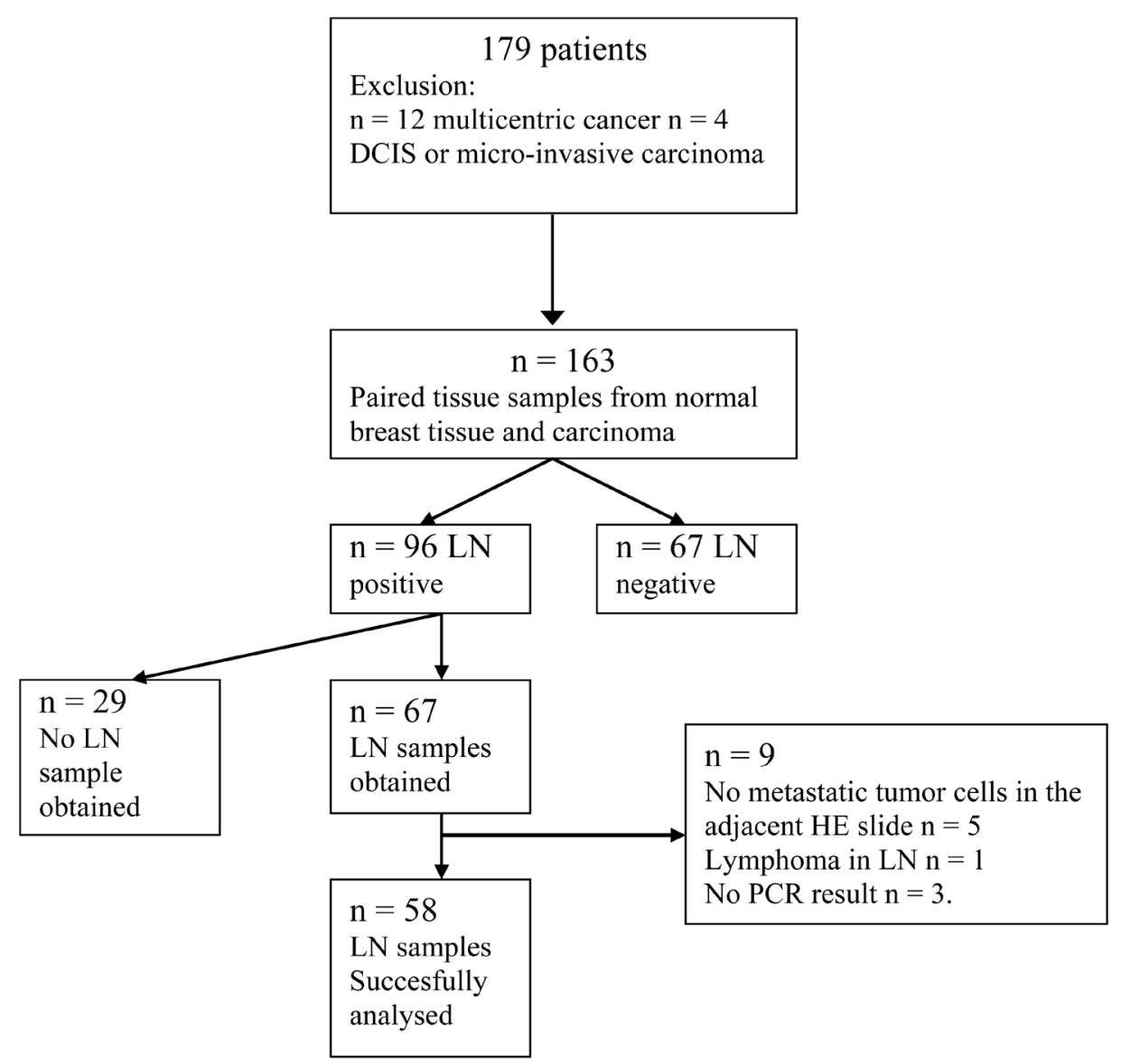

Figure 1. Flow diagram showing included and excluded patients with breast carcinoma, and lymph node status, and the tissue samples obtained. LN: Lymph node. 
Table 1. Clinicopathological characteristics for 163 patients with breast carcinomas. Estrogen and HER2 status was determined by routine diagnostic immunohistochemistry/FISH (see methods section).

\begin{tabular}{|c|c|}
\hline Total number of patients & 163 \\
\hline Gender & Female \\
\hline Age at diagnosis mean, (range) years & $63(32-85)$ \\
\hline \multicolumn{2}{|c|}{ Histology, n (\%) } \\
\hline Invasive ductal carcinoma & 129 (79\%) \\
\hline Invasive lobular carcinoma & $23(14 \%)$ \\
\hline Other & $11(7 \%)$ \\
\hline \multicolumn{2}{|c|}{ Tumor size, n (\%) } \\
\hline$<20 \mathrm{~mm}$ & 89 (55\%) \\
\hline $20 \mathrm{~mm} \leq$ size $<50 \mathrm{~mm}$ & $70(43 \%)$ \\
\hline$\geq 50 \mathrm{~mm}$ & $4(2 \%)$ \\
\hline \multicolumn{2}{|c|}{ Malignancy grade, n (\%) } \\
\hline Grade 1 & $53(32 \%)$ \\
\hline Grade 2 & $58(36 \%)$ \\
\hline Grade 3 & 49 (30\%) \\
\hline Not graded & $3(2 \%)$ \\
\hline \multicolumn{2}{|c|}{ Estrogen receptor status, n (\%) } \\
\hline Positive & $142(87 \%)$ \\
\hline Negative & $21(13 \%)$ \\
\hline \multicolumn{2}{|c|}{ HER2 status, n (\%) } \\
\hline Normal expression & $126(77 \%)$ \\
\hline Overexpression & $15(9 \%)$ \\
\hline Unknown & $22(14 \%)$ \\
\hline \multicolumn{2}{|c|}{ Axillary lymph node status, n (\%) } \\
\hline Lymph node positive & 96 (59\%) \\
\hline Lymph node negative & $67(41 \%)$ \\
\hline
\end{tabular}

Tumor specimens were collected as complete 1 to $2 \mathrm{~mm}$ cross sectional slides and sampled at random into RNase free tubes, and immediately frozen and stored at minus $80^{\circ} \mathrm{C}$. If the tumor diameter exceeded $5 \mathrm{~cm}$, the pathologist chose a representative slide of macroscopically vital tumor. To confirm the content of invasive carcinoma, the adjacent tumor cross sectional slide was immediately fixed in neutral-buffered formalin and prepared for microscopy using an in-house HE staining. The estrogen receptor was stained with the SP1 clone. The IHC HER2 immunostain was PATHWAY (4B5), Ventana, Roche and FISH was performed with HER2 FISH pharmDx, DAKO.

Lymph node samples were complete 20- $\mu \mathrm{m}$ sections collected from either sentinel lymph nodes $(\mathrm{n}=23)$ or axillary dissections $(n=35)$. The adjacent slide was used as a control to confirm the content of metastatic carcinoma. 


\subsection{RNA Extraction from Tissue Samples}

Total RNA was extracted from frozen tissue samples by the principles described by Chomczynski and Sacchi [28]. Due to the adipose nature of breast tissue, optimal RNA extraction was performed using a lipid tissue kit (RNeasy Lipid Tissue Kit, Qiagen). Depending on the individual tissue sample weight, we used the RNeasy midi or mini kits following the manufacturer's instructions. In brief, the tissue samples were homogenized in QIAzol Lysis Reagent on ice. After incubation for 5 minutes at room temperature, $1 \mathrm{ml}$ chloroform was admixed by shaking followed by 5 min centrifugation $(5000 \times g)$ at $4^{\circ} \mathrm{C}$. The aqueous phase, now containing the RNA, was transferred to a fresh tube. An equal volume of $70 \%$ ethanol was added and the suspended RNA was transferred to an RNeasy spin column and centrifuged for $5 \mathrm{~min}$ at $5000 \times \mathrm{g}$. Flow-through was discarded and the membrane washed followed by centrifugation $(5000 \times g)$. While RNA remained bound to the RNeasy membrane, the DNA was removed by DNA digestion. The DNases were removed by buffer washings, each followed by centrifugation ensuring that no residual ethanol was carried over. In a fresh tube, the RNA was finally eluated in RNase free water with 2 centrifugations $(5000 \times g)$.

The yield of total RNA was determined by UV spectrophotometry (absorbance at $260 \mathrm{~nm}$ ).

\subsection{Reverse Transcription}

cDNA was transcribed from the RNA extracted from the tissue samples using oligo (dT) priming. The HER2 analysis was a template specific fluorescent probe assay $\left(\operatorname{taqman}{ }^{\circledR}\right)$.

A total RNA amount of $0.1 \mu \mathrm{g}$ was reversely transcribed in a $20 \mu \mathrm{L}$ reaction mixture containing $2 \mu \mathrm{L} 10 \times$ PCR buffer (Applied Biosystems, Foster City, CA., USA), $5 \mu \mathrm{L} \mathrm{MgCl}_{2}(6.3 \mathrm{mmol} / \mathrm{L}), 8 \mu \mathrm{L}$ of deoxyribonucleoside triphosphates (dATP, dTTP, dGTP, and dCTP, $25 \mathrm{mmol} / \mathrm{L}$ ), $2.5 \mathrm{mmol} / \mathrm{L} \mathrm{16mer} \mathrm{oligo} \mathrm{dT} \mathrm{nucleotide,} 20$ units RNase inhibitor (Applied Biosystems), 50 units reverse transcriptase (Applied Biosystems), and $1 \mu \mathrm{L}$ nuclease free-water.

Reverse transcription was performed in a thermocycler (Gene Amp PCR system 9700, Applied Biosystems) at $42^{\circ} \mathrm{C}$ for 30 minutes followed by $98^{\circ} \mathrm{C}$ for 1 minute, and finally at $4^{\circ} \mathrm{C}$ for 5 minutes. The resulting cDNA was immediately used for RT-PCR, or stored at minus $20^{\circ} \mathrm{C}$.

Analyses of all target genes were performed on the same cDNA preparation, thereby minimizing variation.

\subsection{Real-Time PCR}

The EGF system including HER1-4, CYT1-2, and their activating ligands and the household genes were quantified by real-time PCR with the primers and reaction conditions (Table S1). One $\mu \mathrm{L}$ of the cDNA was used as template and $5 \mu \mathrm{L}$ Light Cycler 480 SYBR green I master mix (Roche Mannheim, GE) supplemented with 0.5 $\mu \mathrm{L}$ sense and antisense primers and probes (Primers and conditions as shown in Table S1). The volume was adjusted to $10 \mu \mathrm{L}$ with nuclease-free water.

The samples were amplified in the Light Cycler 480 system (Roche, Light Cycler software, version 1.5.0), and PCR performed with an initial denaturation step at $95^{\circ} \mathrm{C}$, immediately followed by annealing (annealing temperatures given in Table S1) for 15 seconds. Quantification was done with the second derivate max method by the Light Cycler software.

\subsection{The Calibration Curve}

The LightCycler software constructs calibration curves based on serial dilutions of the individual calibrators in water (calibrators listed in Table S1). The fitted regression line of the calibrator dilution provides the read of the sample concentration. The results are expressed relative to the mRNA content in the calibrator used for generating the calibration curve.

The interassay coefficient of variation (CV) for HER1-HER4 and HMBS was 7\% - 12\%, calculated for 10 real-time PCR runs. For CYT1 and CYT2 and the ligands, it was $4 \%-28 \%$ in 10 runs.

\subsection{Normalization}

In order to standardize initial RNA quantities in different samples, an endogenous reference gene was used for normalization. We used the Microsoft Excel add-in application Norm Finder [29] to rank the gene expression 
stability of 5 household genes. Analyzing the 3 investigated tissue types, normal breast tissue, breast carcinoma, and lymph nodes, for 5 household genes enabled us to identify the most stable reference gene.

\subsection{Identification of the Reference gene}

To determine a stable expressed household gene we examined 85 samples from 35 patients comprising 35 normal specimens, 35 carcinomas, and 15 lymph node samples. The mRNA expressions of hydroxymethylbilane synthase (HMBS), $\beta$-Actin (ACTB), glyceraldehyde-3-phosphate dehydrogenase (GAPDH), tyrosine 3-monooxygenase/ tryptophan 5-monooxygenase activation protein zeta polypeptide (YWHAZ) and beta-2-microglobulin (B2M) were quantified with real-time PCR. The household gene with the most stable expression was identified as HMBS with the NormFinder application [29]. The candidate genes are ranked by the NormFinder application according to their stability values. Based on the results, we employed HMBS as the reference gene for analyses of the EFG receptors and ligands.

\subsection{Statistics}

Data were analyzed using STATA version 10 (StataCorp LP, Texas, USA) and graphic statistic illustrations using GraphPad Prism 5 statistical software package (GraphPad Software Inc., San Diego, CA., USA). A non-parametric test was used to analyze the data. Two-sided P-values less than 0.05 were considered to be significant. Paired analyses of the paired samples were done by Wilcoxon matched-pairs signed-rank test. The correlations of the receptors and their ligands were performed by Spearman non-parametric correlation. Comparison of the lymph node-negative patients and the lymph node-positive patients was performed by Mann-Whitney U-test and Fisher's exact test.

\section{Results}

We examined the mRNA expressions of the four EGF receptors (HER1-HER4) including the 2 HER4 isomeric splicevariants (CYT1 and CYT2), and 11 of their activating ligands in paired samples of normal breast tissue and carcinoma specimens from 163 patients. In 58 of these patients a corresponding metastatic lymph node was obtained for analyses. The clinicopathological characteristics of the patients are described in Table 1.

\subsection{The Receptors}

There was a significant difference in mRNA expression of all four HER receptors comparing normal breast tissue with carcinoma. HER2, HER3, and HER4 (including the two isomeric splicevariants of HER4, CYT1 and CYT2 (data not shown)) were upregulated in carcinomas (Figure 2). In contrast, HER1 showed a significantly higher mRNA expression in the normal breast tissue specimens compared with the carcinomas.

The paired analyses of breast carcinoma versus lymph node metastases showed a significant difference regarding HER3 and HER4, whereas there was no difference in the expression of HER1 and HER2 between the 2 locations (Figure 2).

\subsection{Receptor Correlations between the 3 Locations}

The receptors were individually correlated between the 3 different locations from which the tissue samples had been obtained. Significant correlations between primary carcinoma and the lymph node metastases were found for all receptors except HER3 (Table 2). Between normal breast tissue and carcinoma, only HER1 showed a significant correlation.

\subsection{Combinations of Receptors Were Correlated within the 3 Locations}

The mRNA expressions of any combination of HER2, HER3, and HER4 were all highly significantly correlated $(\mathrm{P}<0.05)$ in normal breast tissue as well as in carcinoma (Table 3), while any combinations of receptors involving HER1 did not show significant correlations.

Interestingly, in the lymph node metastases the expression of HER3-HER4 was the only receptor combination that showed a significant correlation. 

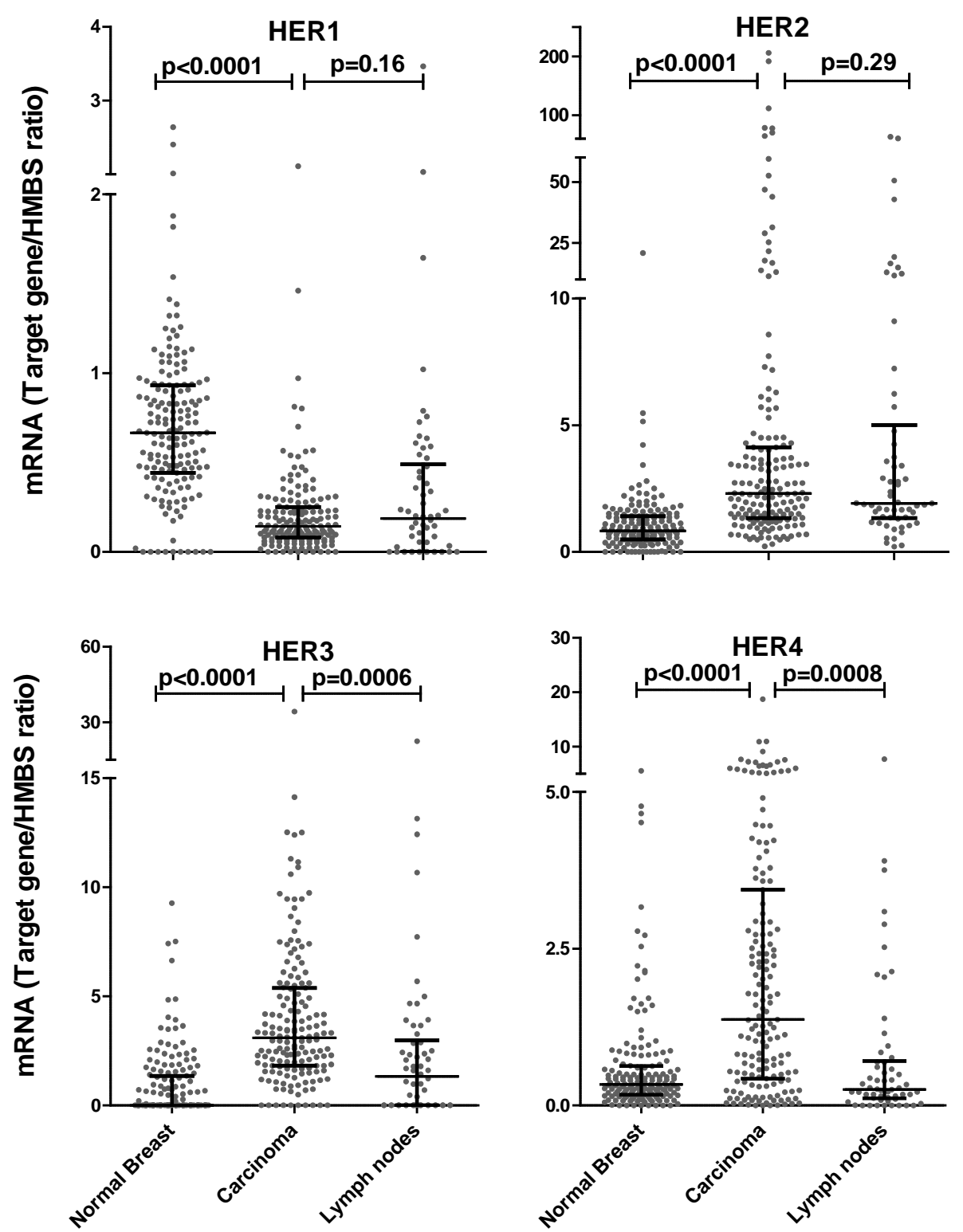

Figure 2. Paired expression of HER1-4 at 3 locations in breast cancer patients: Normal breast tissue $(n=163)$, breast carcinoma $(n=163)$, and lymph node metastases $(n=58)$. All data are the ratio of the target gene and the household gene, HMBS, given in arbitrary units. Medians with interquartile ranges are presented. $\mathrm{P}$ values were determined by Wilcoxon matched-pairs signed-rank test. Note: units are non-comparable between receptors.

Table 2. Correlations of the expression of the EGF receptors between the 3 locations by Spearman non-parametric correlation. Significant P values are marked with asterisks.

\begin{tabular}{ccccc} 
& \multicolumn{2}{c}{ Normal breast-carcinoma $(\mathrm{n}=163)$} & \multicolumn{2}{c}{ Carcinoma-lymph node metastasis $(\mathrm{n}=58)$} \\
\cline { 2 - 5 } & Correlation & P value & Correlation & P value \\
\hline HER1 & 0.19 & $0.013^{*}$ & 0.48 & $<0.0001^{*}$ \\
HER2 & 0.083 & 0.29 & 0.58 & $<0.0001^{*}$ \\
HER3 & 0.14 & 0.073 & 0.15 & 0.28 \\
HER4 & 0.12 & 0.14 & 0.29 & $0.026^{*}$ \\
\hline
\end{tabular}


Table 3. Correlations of the paired expressions of HER1-HER4 within 3 locations in breast cancer patients: Normal breast tissue $(n=163)$, breast carcinoma $(n=163)$, and lymph node metastases $(n=58)$. Analysed by Spearman non-parametric correlation. Significant $\mathrm{P}$ values are marked with asterisks.

\begin{tabular}{lcccccc} 
& \multicolumn{2}{c}{ Normal breast tissue } & \multicolumn{2}{c}{ Breast carcinoma } & \multicolumn{2}{c}{ Lymph node metastases } \\
\cline { 2 - 7 } & Correlation & P value & Correlation & P value & Correlation & P value \\
\hline HER1-HER2 & 0.085 & 0.28 & -0.063 & 0.42 & -0.12 & 0.36 \\
HER1-HER3 & -0.007 & 0.93 & 0.079 & 0.31 & 0.16 & 0.22 \\
HER1-HER4 & 0.012 & 0.88 & 0.020 & 0.80 & 0.12 & 0.35 \\
HER2-HER3 & 0.39 & $<0.0001^{*}$ & 0.28 & $0.0003^{*}$ & 0.23 & 0.081 \\
HER2-HER4 & 0.49 & $<0.0001^{*}$ & 0.16 & $0.041^{*}$ & 0.062 & 0.64 \\
HER3-HER4 & 0.47 & $<0.0001^{*}$ & 0.50 & $<0.0001^{*}$ & 0.54 & $<0.0001^{*}$ \\
\hline
\end{tabular}

\subsection{Receptors in Lymph Node-Positive and Lymph Node-Negative Patients}

We explored the difference in EGF receptor expressions in the primary carcinomas for lymph node-negative patients $(n=67)$ as compared to lymph node-positive patients $(n=96)$. No difference was observed between the groups for any of the individual receptors. However, the combination of low HER3 and low HER4 expression in the primary carcinoma was significantly more frequent in lymph node-negative patients than in lymph nodepositive patients, the distribution is indicated in Table 4_(Fisher’s exact test, $\mathrm{P}=0.011$ ).

\subsection{The Ligands}

We observed significant different expression levels between normal breast tissue and carcinoma, and between carcinoma and lymph node metastases, for the majority of the ligands. As compared to normal breast tissue we found breast tumors to show an upregulation for AMPH and EPI and a downregulation for HB-EGF and all neuregulins except NRG3. TGF- $\alpha$ and NRG3 showed no difference in expression levels between the 3 locations.

Data for all the ligands investigated are given in Figure S1.

\subsection{Correlations of the Receptors and Their Activating Ligands}

The correlation of the individual receptors and their activating ligands are listed in Table S2. HER1 correlated with HB-EGF in normal breast tissue, and this was also seen in carcinoma specimens in which AMPH/HER1 was also correlated.

In normal breast tissue HER3 correlated with NRG1 $\alpha$, NRG1 $\beta$, NRG2 $\alpha$, and NRG3. HER4 correlated with NRG1 $\alpha$, NRG1 $\beta$, NRG2 $\alpha$, NRG2 $\beta$, and NRG3.

In carcinoma both HER3 and HER4 correlated with NRG2 $\alpha$ and NRG4. Additionally, HER4 correlated with HB-EGF and NRG2 $\beta$.

Notably, we could demonstrate correlation patterns for the ligands in both normal breast tissue and in the carcinoma. As a HER1 and HER4 activator, HB-EGF proved to be correlated to HER1 in both locations, even though HER1 showed a low mRNA expression in carcinomas. Furthermore, HB-EGF and HER4 correlations appeared in the carcinomas. Likewise, NRG2 $\alpha$ and NRG4 remained correlated to both of the 2 receptors that these ligands can activate (HER3 and HER4), and for HER4 the NRG2 $\beta$ correlation was also retained.

The correlations of NRG1 $\alpha, 1 \beta$, and NGR3 with both HER3 and HER4 were not repeated in the carcinoma specimens or in the metastatic lymph nodes.

\section{Discussion}

In this prospective cohort study of tissue samples from breast cancer patients, we have investigated the expression patterns of receptors and ligands of the EGF system. Comparison of normal breast tissue and carcinoma showed a significant upregulation in the mRNA expression of HER2, HER3, and HER4, whereas HER1 was downregulated in carcinomas. HER2 and HER3 mRNA overexpression in carcinomas is supported by previous 
Table 4. Distribution of patients with the combination of low mRNA expression of HER3/HER4 and their lymph node status in patients with breast cancer $(\mathrm{n}=163)$. ${ }^{*}$ Fisher's exact test $(\mathrm{P}=0.011)$.

\begin{tabular}{cccc}
\hline & \multicolumn{3}{c}{ Low HER3 and low HER4 } \\
\cline { 2 - 4 } & Low & High & Total \\
\hline +LN metastases & 25 & 71 & $96^{*}$ \\
-LN metastases & 31 & 36 & $67^{*}$ \\
Total & 56 & 107 & 163 \\
\hline
\end{tabular}

reports describing co-expression, high prevalence, and potent mitogenic signaling of this particular heterodimer in breast cancer [31]-[33]. HER3 stands out as the only EGF receptor lacking intracellular tyrosine kinase activity, but recent evidence from experimental models suggest that its non-catalytic functions are critical for cancers driven by the EGF receptor partners [34] [35]. Therefore, the importance of HER3 is being revisited [36] [37]. In a study of 278 tissue samples from breast cancer patients correlating IHC and FISH to survival, Sassen et al. found HER3 to have a negative impact on disease-free survival [19]. We confirm that HER2 and HER3 are overexpressed and significantly co-expressed in breast carcinomas; a prerequisite to be the most prevalent heterodimer [38]. Also, HER3 was significantly correlated to the mRNA expression of the HER3 activating ligands, NRG2 $\alpha$ and NRG4, in breast carcinoma. Considering this to indicate a high protein expression of both receptors and ligands these findings imply that an active signaling network using these 2 ligands and HER2 and HER3 is present.

We report HER4 overexpression in primary carcinomas, in accord with previous results [33]. The functional significance of this is controversial [39]. The HER4 receptor appears to possess divergent functions demonstrated in vitro to depend on the isoform of the receptor [40] [41]. The HER4 response can also depend on the activating ligand [42], or the localization in the cell compartments (membrane bound, cytoplasmatic or in the nucleus) [43]. Changes in HER4 expression during the metastatic process [10] [44] lead to the conclusion that the HER4 receptor is adaptable and that the cell response can be different depending on the stimuli.

The HER1 receptor was the only of the EGF receptors in our study that showed a lower expression in the carcinomas compared with the normal breast tissue. Low HER1 mRNA expression in breast carcinoma has also been reported by Witton et al. [33]. Witton reports that patients with mRNA overexpression of HER1 and a HER1 positive IHC staining (16\% of all cases) had reduced overall survival. The role of HER1 as a carcinogenic driver in breast cancer is well established [45] but the apparent carcinoma downregulation and presumed alternation in function has yet to be explored.

Our paired analyses between primary carcinoma and lymph node metastases showed that HER1 and HER2 were not significantly altered in expression but highly correlated. These findings provide important support for the current clinical practice for evaluating HER2 in the primary breast carcinomas on the assumptions that the protein expressions are identical to those in the minimal residual disease. In other words, the targets of the postoperative adjuvant therapy with Herceptin and Lapatinib are assumed to be present in the minimal residual disease when overexpressed in the primary carcinoma. Obviously this conclusion based on our quantitative mRNA measurements will have to be further validated in clinical trials.

Although, the mRNA expression of HER3 and HER4 are significantly lower in normal breast tissue than in the primary carcinoma, the expression of the receptors are significantly correlated at both sites. Interestingly, this correlation pattern of HER3 and HER4 was the only one to reoccur in the lymph node metastases. Combined with the mRNA expressions of the HER3 and HER4 activating ligands we describe plausible transformations of the EGF system during neoplastic progression.

The carcinomas maintain and increase several of the EGF expression patterns of normal breast tissue (Figure 2 and Table 2). Only bipotent ligands (HB-EGF, NRG2 $\alpha, 2 \beta$, and NRG4) capable of activating more than one receptor type and AMPH (the only ligand showing a highly significant increase in mRNA expression (Figure S1)) correlated to the receptors they activate in breast cancer. These findings regarding HB-EGF, AMPH, and NRG2 expression in breast cancer concur with the ligand study by Révillion et al. [46], but the correlation to the receptors they can activate has not been described previously. 
The numerous described characteristics of normal breast tissue that are also seen in carcinoma specimens are not present in the lymph node metastases, with the exception of the HER3-HER4 correlation. The expression levels of the neuregulins cover a considerably wider range in the lymph node metastases than in the carcinomas, exemplified by NRG2 $\alpha$ and NRG3 in Figure S1. We assume that in the lymph node metastases the activating ligands would either come from the tumor cells or from the blood supply because stromal cells are not always present. The alterations of the expression of the EGF system in the lymph node metastases point to the carcinoma surroundings as the most obvious physical difference between the carcinoma of the breast and the lymph node metastases. Stromal-epithelial interactions are characteristic of breast carcinomas, but juxtacrine signaling mechanisms are also a possible alternative way of receptor activation [47].

The expression of the individual EGF receptors in the primary tumor could not discriminate lymph nodepositive patients from lymph node-negative patients. However, the combination of low expression of HER3 and HER4 in the primary carcinomas could distinguish the 2 groups. The combination of low HER3 and HER4 expression in the primary carcinoma was significantly more frequent in lymph node-negative patients than in lymph node-positive patients, and we interpret this as a positive prognostic indicator. On the other hand, in the primary carcinoma HER3 and HER4 could promote tumor growth by ligand specific activation of NRG2 $\alpha$ and NRG4.

In conclusion, HER2, HER3, and HER4 showed increased mRNA expression in carcinoms and were positively correlated to each other and to specific activating ligands. The combination of low HER3 and low HER4 expression in the primary carcinoma was significantly more frequent in lymph node-negative patients as compared to lymph node positive patients.

\section{Conflicts of Interest}

The authors declare that they have no conflict of interest.

\section{Acknowledgments}

The authors thank Ann Skjødt Pedersen and Birgit Nielsen, Institute of Pathology, Aalborg Hospital, and Lene Dabelstein Petersen and Birgit Westh Mortensen, Department of Clinical Biochemistry, Aarhus University Hospital, for their excellent technical assistance.

The dedication of the breast team surgeons has been exceptional; our appreciation goes to Liselotte Jeppesen, Karen Haugaard and Hanne Bygbjerg and the staffs at the breast surgery ward and in the operating room.

\section{Grant Support}

Breast Friends, Roche; Region Midtjyllands Health Research Foundation; Henny Sophie Clausen og Møbelarkitekt Axel Clausens Foundation; Nordjyllands Lægekredsforenings Research Foundation; Aalborg Hospital Foundation for Young Doctors; Danish Agency for Science, Technology and Innovation; Grant from North Denmark Region; Ebba og Aksel Shølins Foundation; Dr. Heinrich Kopp’s Grant.

\section{References}

[1] Zahnow, C.A. (2006) ErbB Receptors and Their Ligands in the Breast. Expert Reviews in Molecular Medicine, 23, 121.

[2] Kalous, O., Conklin, D., Desai, A.J., O’Brien, N.A., Ginther, C., Anderson, L., et al. (2012) Dacomitinib (PF00299804), an Irreversible Pan-HER Inhibitor, Inhibits Proliferation of HER2-Amplified Breast Cancer Cell Lines Resistant to Trastuzumab and Lapatinib. Molecular Cancer Therapeutics, 9, 1978-1987. http://dx.doi.org/10.1158/1535-7163.MCT-11-0730

[3] McGuire, W.L. (1987) Prognostic Factors for Recurrence and Survival in Human Breast Cancer. Breast Cancer Research and Treatment, 1, 5-9. http://dx.doi.org/10.1007/BF01806129

[4] Carter, C.L., Allen, C. and Henson, D.E. (1989) Relation of Tumor Size, Lymph Node Status, and Survival in 24, 740 Breast Cancer Cases. Cancer, 1, 181-187. http://dx.doi.org/10.1002/1097-0142(19890101)63:1<181::AID-CNCR2820630129>3.0.CO;2-H

[5] Li, J., Gromov, P., Gromova, I., Moreira, J.M., Timmermans-Wielenga, V., Rank, F., et al. (2008) Omics-Based Profiling of Carcinoma of the Breast and Matched Regional Lymph Node Metastasis. Proteomics, 23-24, 5038-5052. http://dx.doi.org/10.1002/pmic.200800303 
[6] Santinelli, A., Pisa, E., Stramazzotti, D. and Fabris, G. (2008) HER-2 Status Discrepancy between Primary Breast Cancer And Metastatic Sites. Impact on target therapy. International Journal of Cancer, 5, 999-1004.

[7] Vecchi, M., Confalonieri, S., Nuciforo, P., Vigano, M.A., Capra, M., Bianchi, M., et al. (2008) Breast Cancer Metastases Are Molecularly Distinct from their Primary Tumors. Oncogene, 15, 2148-2158. http://dx.doi.org/10.1038/sj.onc.1210858

[8] Feng, Y., Sun, B., Li, X., Zhang, L., Niu, Y., Xiao, C., et al. (2007) Differentially Expressed Genes between Primary Cancer and Paired Lymph Node Metastases Predict Clinical Outcome of Node-Positive Breast Cancer Patients. Breast Cancer Research and Treatment, 3, 319-329. http://dx.doi.org/10.1007/s10549-006-9385-7

[9] Pandit, T.S., Kennette, W., Mackenzie, L., Zhang, G., Al-Katib, W., Andrews, J., et al. (2009) Lymphatic Metastasis of Breast Cancer Cells Is Associated with Differential Gene Expression Profiles That Predict Cancer Stem Cell-Like Properties and the Ability to Survive, Establish and Grow in a Foreign Environment. International Journal of Oncology, 2, 297-308.

[10] Fuchs, I.B., Siemer, I., Buhler, H., Schmider, A., Henrich, W., Lichtenegger, W., et al. (2006) Epidermal Growth Factor Receptor Changes during Breast Cancer Metastasis. Anticancer Research, 6B, 4397-4401.

[11] Cardoso, F., Di, L.A., Larsimont, D., Gancberg, D., Rouas, G., Dolci, S., et al. (2001) Evaluation of HER2, p53, bcl-2, Topoisomerase II-Alpha, Heat Shock Proteins 27 and 70 in Primary Breast Cancer and Metastatic Ipsilateral Axillary Lymph Nodes. Annals of Oncology, 5, 615-620. http://dx.doi.org/10.1023/A:1011182524684

[12] Stern, D.F. (2003) ErbBs in Mammary Development. Experimental Cell Research, 1, 89-98. http://dx.doi.org/10.1016/S0014-4827(02)00103-9

[13] Paez, J.G., Janne, P.A., Lee, J.C., Tracy, S., Greulich, H., Gabriel, S., et al. (2004) EGFR Mutations in Lung Cancer, Correlation with Clinical Response to Gefitinib Therapy. Science, 5676, 1497-1500. http://dx.doi.org/10.1126/science.1099314

[14] Bang, Y.J, Van, C.E., Feyereislova, A., Chung, H.C., Shen, L., Sawaki, A., et al. (2010) Trastuzumab in Combination with Chemotherapy versus Chemotherapy Alone for Treatment of HER2-Positive Advanced Gastric or Gastro-Oesophageal Junction Cancer (ToGA): a Phase 3, Open-Label, Randomised Controlled Trial. Lancet, 9742, 687-697. http://dx.doi.org/10.1016/S0140-6736(10)61121-X

[15] Siena, S., Sartore-Bianchi, A., Di, N.F., Balfour, J. and Bardelli, A. (2009) Biomarkers Predicting Clinical Outcome of Epidermal Growth Factor Receptor-Targeted Therapy in Metastatic Colorectal Cancer. Journal of the National Cancer Institute, 19, 1308-1324. http://dx.doi.org/10.1093/jnci/djp280

[16] Riese, D.J. and Stern, D.F. (1998) Specificity within the EGF Family/ErbB Receptor Family Signaling Network. Bioessays, 1, 41-48. http://dx.doi.org/10.1002/(SICI)1521-1878(199801)20:1<41::AID-BIES7>3.0.CO;2-V

[17] Citri, A. and Yarden, Y. (2006) EGF-ERBB Signalling: Towards the Systems Level. Nature Reviews Molecular Cell Biology, 7, 505-516. http://dx.doi.org/10.1038/nrm1962

[18] Wilson, K.J., Gilmore, J.L., Foley, J., Lemmon, M.A. and Riese, D.J. (2009) Functional Selectivity of EGF Family Peptide Growth Factors: Implications for Cancer. Pharmacology \& Therapeutics, 1, 1-8. http://dx.doi.org/10.1016/j.pharmthera.2008.11.008

[19] Sassen, A., Rochon, J., Wild, P., Hartmann, A., Hofstaedter, F., Schwarz, S., et al. (2008) Cytogenetic Analysis of HER1/EGFR, HER2, HER3 and HER4 in 278 Breast Cancer Patients. Breast Cancer Research, 1, R2. http://dx.doi.org/10.1186/bcr1843

[20] McIntyre, E., Blackburn, E., Brown, P.J., Johnson, C.G. and Gullick, W.J. (2010) The Complete Family of Epidermal Growth Factor Receptors and Their Ligands Are Co-Ordinately Expressed in Breast Cancer. Breast Cancer Research and Treatment, 1, 105-110. http://dx.doi.org/10.1007/s10549-009-0536-5

[21] Carlsson, J., Nordgren, H, Sjostrom, J., Wester, K., Villman, K. and Bengtsson, N.O., et al. (2004) HER2 Expression in Breast Cancer Primary Tumours and Corresponding Metastases. Original Data and Literature Review. British Journal of Cancer, 12, 2344-2348.

[22] Gancberg, D., Di, L.A., Cardoso, F., Rouas, G., Pedrocchi, M. and Paesmans, M., et al. (2002) Comparison of HER-2 Status between Primary Breast Cancer and Corresponding Distant Metastatic Sites. Annals of Oncology, 7, 1036-1043. http://dx.doi.org/10.1093/annonc/mdf252

[23] Gong, Y., Booser, D.J. and Sneige, N. (2005) Comparison of HER-2 Status Determined by Fluorescence in Situ Hybridization in Primary and Metastatic Breast Carcinoma. Cancer, 9, 1763-1769. http://dx.doi.org/10.1002/cncr.20987

[24] Tapia, C., Savic, S., Wagner, U., Schonegg, R., Novotny, H. and Grilli, B., et al. (2007) HER2 Gene Status in Primary Breast Cancers and Matched Distant Metastases. Breast Cancer Research, 3, 31. http://dx.doi.org/10.1186/bcr1676

[25] Zidan, J., Dashkovsky, I., Stayerman, C., Basher, W., Cozacov, C. and Hadary, A. (2005) Comparison of HER-2 Overexpression in Primary Breast Cancer and Metastatic Sites and Its Effect on Biological Targeting Therapy of Me- 
tastatic Disease. British Journal of Cancer, 5, 552-556. http://dx.doi.org/10.1038/sj.bjc.6602738

[26] Santiago, M.P., Vazquez-Boquete, A., Fernandez, B., Masa, C., Antunez, J.R. and Fraga, M., et al. (2009) Whether to Determine HER2 Status for Breast Cancer in the Primary Tumour or in the Metastasis. Histology and Histopathology, 6, 675-682.

[27] Ohashi, Y., Creek, K.E., Pirisi, L., Kalus, R. and Young, S.R. (2004) RNA Degradation in Human Breast Tissue after Surgical Removal: A Time-Course Study. Experimental and Molecular Pathology, 2, 98-103. http://dx.doi.org/10.1016/j.yexmp.2004.05.005

[28] Chomczynski, P. and Sacchi, N. (1987) Single-Step Method of RNA Isolation by Acid Guanidinium ThiocyanatePhenol-Chloroform Extraction. Analytical Biochemistry, 1, 156-159. http://dx.doi.org/10.1016/0003-2697(87)90021-2

[29] Andersen, C.L., Jensen, J.L. and Orntoft, T.F. (2004) Normalization of Real-Time Quantitative Reverse Transcription-PCR Data: A Model-Based Variance Estimation Approach to Identify Genes Suited for Normalization, Applied to Bladder and Colon Cancer Data Sets. Cancer Research, 15, 5245-5250. http://dx.doi.org/10.1158/0008-5472.CAN-04-0496

[30] Holbro, T., Beerli, R.R., Maurer, F., Koziczak, M., Barbas III, C.F. and Hynes, N.E. (2003) The ErbB2/ErbB3 Heterodimer Functions as an Oncogenic Unit: ErbB2 Requires ErbB3 to Drive Breast Tumor Cell Proliferation. Proceedings of National Academy of Science of the United States of America, 15, 8933-8938. http://dx.doi.org/10.1073/pnas.1537685100

[31] Gasparini, G., Gullick, W.J., Maluta, S., Dalla, P.P., Caffo, O. and Leonardi, E., et al. (1994) c-erbB-3 and c-erbB-2 Protein Expression in Node-Negative Breast Carcinoma-An Immunocytochemical Study. European Journal of Cancer, 1, 16-22. http://dx.doi.org/10.1016/S0959-8049(05)80010-3

[32] Travis, A., Pinder, S.E., Robertson, J.F., Bell, J.A., Wencyk, P. and Gullick, W.J., et al. (1996) C-erbB-3 in Human Breast Carcinoma: Expression and Relation to Prognosis and Established Prognostic Indicators. British Journal of Cancer, 2, 229-233. http://dx.doi.org/10.1038/bjc.1996.342

[33] Witton, C.J., Reeves, J.R., Going, J.J., Cooke, T.G. and Bartlett, J.M. (2003) Expression of the HER1-4 Family of Receptor Tyrosine Kinases in Breast Cancer. The Journal of Pathology, 3, 290-297. http://dx.doi.org/10.1002/path.1370

[34] Amin, D.N., Campbell, M.R. and Moasser, M.M. (2010) The Role of HER3, the Unpretentious Member of the HER Family, in Cancer Biology and Cancer Therapeutics. Seminars in Cell \& Developmental Biology, 9, 944-950. http://dx.doi.org/10.1016/j.semcdb.2010.08.007

[35] Garrett, J.T., Olivares, M.G., Rinehart, C., Granja-Ingram, N.D., Sanchez, V. and Chakrabarty, A., et al. (2011) Transcriptional and Posttranslational Up-Regulation of HER3 (ErbB3) Compensates for Inhibition of the HER2 Tyrosine Kinase. Proceedings of National Academy of Science of the United States of America, 12, 5021-5026. http://dx.doi.org/10.1073/pnas.1016140108

[36] Garrett, J.T., Sutton, C.R., Kuba, M.G., Cook, R.S. and Arteaga, C.L. (2013) Dual Blockade of HER2 in HER2-Overexpressing Tumor Cells Does Not Completely Eliminate HER3 Function. Clinical Cancer Research, 3, 610-619. http://dx.doi.org/10.1158/1078-0432.CCR-12-2024

[37] Vaught, D.B., Stanford, J.C., Young, C., Hicks, D.J., Wheeler, F. and Rinehart, C., et al. (2012) HER3 is Required for HER2-Induced Preneoplastic Changes to the Breast Epithelium and Tumor Formation. Cancer Research, 10, 26722682. http://dx.doi.org/10.1158/0008-5472.CAN-11-3594

[38] Citri, A., Skaria, K.B. and Yarden, Y. (2003) The Deaf and the Dumb: The Biology of ErbB-2 and ErbB-3. Experimental Cell Research, 1, 54-65. http://dx.doi.org/10.1016/S0014-4827(02)00101-5

[39] Earp III, H.S., Calvo, B.F. and Sartor, C.I. (2003) The EGF Receptor Family-Multiple Roles in Proliferation, Differentiation, and Neoplasia with an Emphasis on HER4. Transactions of the American Clinical and Climatological Association, 315-333.

[40] Jones, F.E. (2008) HER4 Intracellular Domain (4ICD) Activity in the Developing Mammary Gland and Breast Cancer. Journal of Mammary Gland Biology and Neoplasia, 2, 247-258. http://dx.doi.org/10.1007/s10911-008-9076-6

[41] Muraoka-Cook, R.S., Sandahl, M.A., Strunk, K.E., Miraglia, L.C., Husted, C. and Hunter, D.M., et al. (2009) ErbB4 Splice Variants Cyt1 and Cyt2 Differ by 16 Amino Acids and Exert Opposing Effects on the Mammary Epithelium in Vivo. Molecular and Cellular Biology, 18, 4935-4948.

[42] Sartor, C.I., Zhou, H., Kozlowska, E., Guttridge, K., Kawata, E. and Caskey, L., et al. (2001) Her4 Mediates ligand-Dependent Antiproliferative and Differentiation Responses in Human Breast Cancer Cells. Molecular and Cellular Biology, 13, 4265-4675.

[43] Thor, A.D., Edgerton, S.M. and Jones, F.E. (2009) Subcellular Localization of the HER4 Intracellular Domain, 4ICD, Identifies Distinct Prognostic Outcomes for Breast Cancer Patients. American Journal of Pathology, 5, 1802-1809.

[44] Das, P.M., Thor, A.D., Edgerton, S.M., Barry, S.K., Chen, D.F. and Jones, F.E. (2010) Reactivation of Epigenetically 
Silenced HER4/ERBB4 Results in Apoptosis of Breast Tumor Cells. Oncogene, 37, 5214-5219.

[45] Foley, J., Nickerson, N.K., Nam, S., Allen, K.T., Gilmore, J.L. and Nephew, K.P., et al. (2010) EGFR Signaling in Breast Cancer: Bad to the Bone. Seminars in Cell \& Developmental Biology, 9, 951-960.

[46] Revillion, F., Lhotellier, V., Hornez, L., Bonneterre, J. and Peyrat, J.P. (2008) ErbB/HER Ligands in Human Breast Cancer, and Relationships with Their Receptors, the Bio-Pathological Features and Prognosis. Annals of Oncology, 1, 73-80.

[47] Dong, J., Opresko, L.K., Chrisler, W., Orr, G., Quesenberry, R.D. and Lauffenburger, D.A., et al. (2005) The Membrane-Anchoring Domain of Epidermal Growth Factor Receptor Ligands Dictates Their Ability to Operate in Juxtacrine Mode. Molecular Biology of the Cell, 6, 2984-2998. 


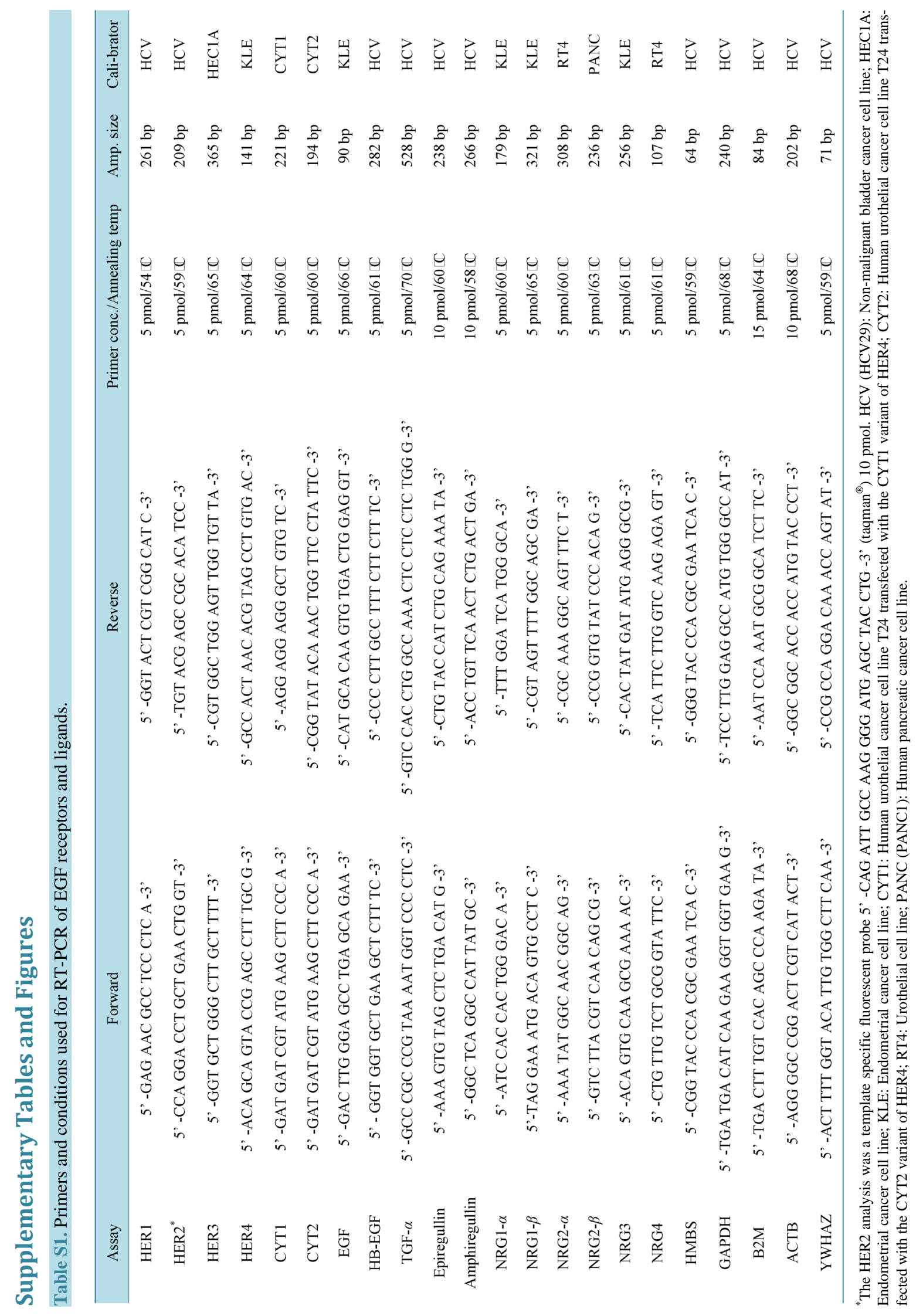



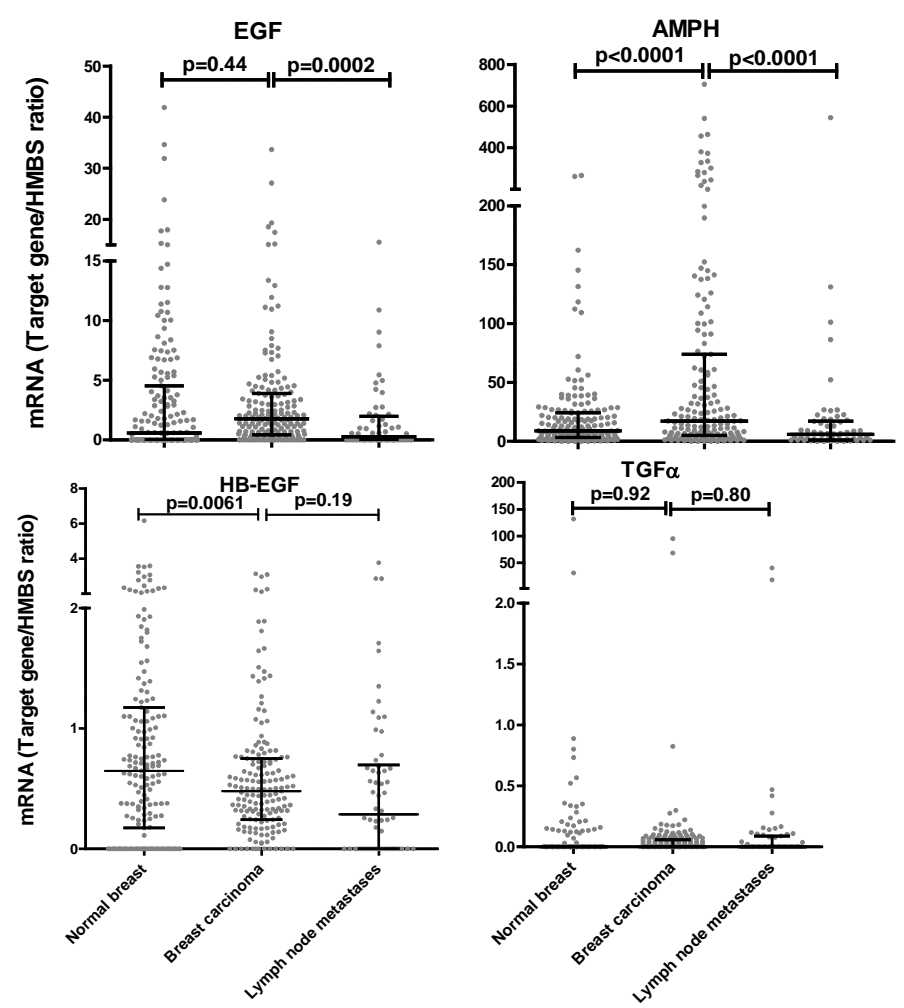

(a)
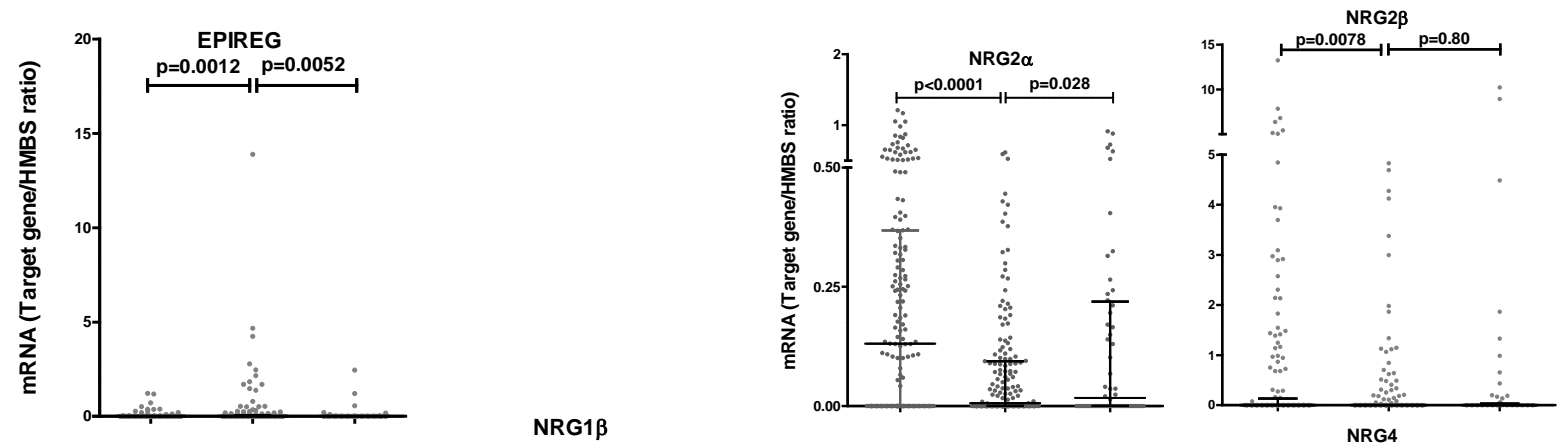

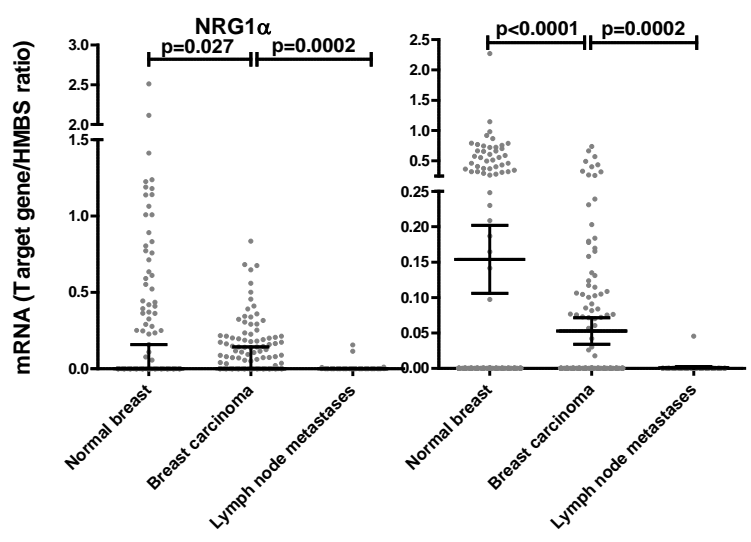

(b)
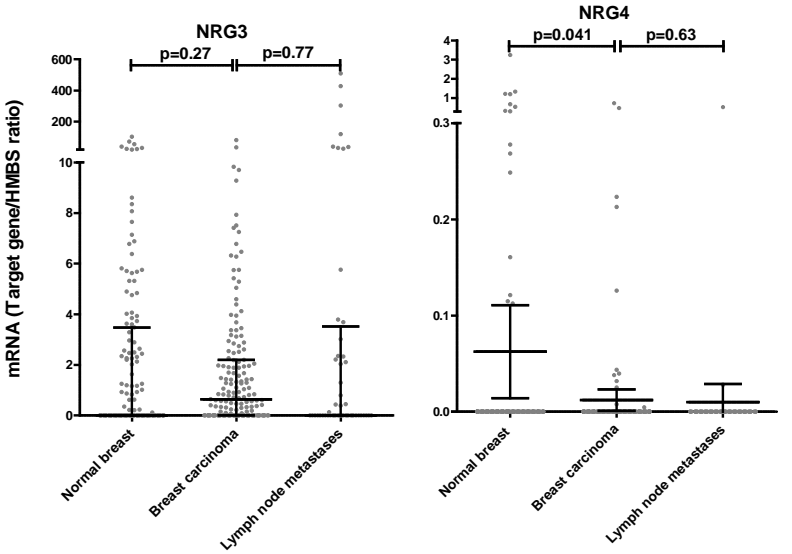

(c)

Figure S1. Expression of 11 EGFR family ligands in 3 locations in breast cancer patients: Normal breast tissue ( $\mathrm{n}=163)$, breast carcinoma $(n=163)$, and lymph node metastases $(n=58)$. All data are the ratio of the target gene and HMBS given in arbitrary units. Medians with interquartile ranges are presented. $\mathrm{P}$ values determined by Wilcoxon matched-pairs signed-rank test. 
Table S2. Correlations of the expression of the EGF receptors and their activating ligands in normal breast tissue ( $\mathrm{n}=$ 163 , breast carcinomas $(n=163)$ and lymph node metastases $(n=58)$ of breast cancer patients. The correlations are determined by Spearman non-parametric correlation. Significant $\mathrm{P}$ values are marked with asterisks.

\begin{tabular}{|c|c|c|c|c|c|c|c|}
\hline \multirow[b]{2}{*}{ Receptor } & \multirow[b]{2}{*}{ Activating ligand } & \multicolumn{2}{|c|}{ Normal breast tissue } & \multicolumn{2}{|c|}{ Breast carcinoma } & \multicolumn{2}{|c|}{ Lymph node metastases } \\
\hline & & Correlation & $P$ value & Correlation & $\mathrm{P}$ value & Correlation & $\mathrm{P}$ value \\
\hline \multirow[t]{5}{*}{ HER1 } & EGF & -0.052 & 0.51 & 0.11 & 0.17 & 0.019 & 0.89 \\
\hline & AMPH & 0.092 & 0.25 & 0.27 & $0.0005^{*}$ & 0.073 & 0.59 \\
\hline & HB-EGF & 0.42 & $<0.0001^{*}$ & 0.43 & $<0.0001^{*}$ & 0.23 & 0.09 \\
\hline & TGF- $\alpha$ & -0.12 & 0.13 & 0.086 & 0.27 & 0.099 & 0.46 \\
\hline & EPIREG & 0.025 & 0.75 & -0.017 & 0.83 & 0.062 & 0.64 \\
\hline \multirow[t]{6}{*}{ HER3 } & NRG1 $\alpha$ & 0.42 & $<0.0001^{*}$ & 0.12 & 0.11 & 0.11 & 0.42 \\
\hline & NRG1 $\beta$ & 0.18 & $0.021^{*}$ & -0.086 & 0.28 & 0.16 & 0.23 \\
\hline & NRG $2 \alpha$ & 0.23 & $0.0027^{*}$ & 0.20 & $0.011^{*}$ & 0.12 & 0.38 \\
\hline & NRG2 $\beta$ & 0.011 & 0.89 & 0.061 & 0.44 & -0.041 & 0.76 \\
\hline & NRG3 & 0.23 & $0.0036^{*}$ & 0.022 & 0.78 & -0.071 & 0.59 \\
\hline & NRG4 & -0.064 & 0.42 & -0.26 & $0.0010^{*}$ & 0.14 & 0.29 \\
\hline \multirow[t]{8}{*}{ HER4 } & HB-EGF & 0.099 & 0.21 & 0.22 & $0.0048^{*}$ & 0.25 & 0.055 \\
\hline & EPIREG & 0.15 & 0.054 & 0.11 & 0.17 & -0.014 & 0.92 \\
\hline & NRG1 $\alpha$ & 0.23 & $0.0037^{*}$ & 0.11 & 0.16 & -0.090 & 0.50 \\
\hline & NRG1 $\beta$ & 0.20 & $0.0093^{*}$ & 0.047 & 0.55 & 0.13 & 0.33 \\
\hline & NRG $2 \alpha$ & 0.32 & $<0.0001^{*}$ & 0.24 & $0.0017^{*}$ & 0.14 & 0.30 \\
\hline & NRG2 $\beta$ & -0.19 & $0.017^{*}$ & 0.19 & $0.019^{*}$ & -0.07 & 0.60 \\
\hline & NRG3 & 0.023 & $0.0029^{*}$ & 0.14 & 0.083 & 0.013 & 0.92 \\
\hline & NRG4 & -0.073 & 0.36 & -0.22 & $0.0046^{*}$ & -0.22 & 0.096 \\
\hline
\end{tabular}

